\title{
Review of Current Developments on Natural and Synthetic Biodegradable Polymers and Their Biomedical Applications
}

\author{
Dr. Piyush M. Maurya* \\ Lecturer, Department of General Science \& Humanities Zeal Education Society's Zeal Polytechnic, Pune, Maharashtra, India \\ ${ }^{*}$ Corresponding Author \\ Dr. Piyush M. Maurya
}

\section{Article History}

Received: 02.10.2019

Accepted: 09.10.2019

Published: 05.11.2019

\begin{abstract}
Bio-based polymers are attracting improved interest due to environmental concerns and the realization that global petroleum assets are finite. Plastic is one of the main pollutants at gift time round the sector that is used for day by day use like packaging materials, deliver bags, manufacturing of various forms of substances and many others. A number of bio-based polymers are supplied on this evaluate, that specialize in trendy methods of production, properties, and commercial packages. Despite the fact that polymers are used substantially as pharmaceutical packaging; this evaluate is involved with the usage of polymers in the formula of various dosage forms. Improvement of biodegradable polymer frameworks offers the good sized favorable function of empowering either web page-particular or systemic corporation of pharmaceutical operators without the requirement for ensuing healing of the conveyance framework.
\end{abstract}

Keywords: Bio-based polymers, renewable resources, biodegradable polymers.

\section{INTRODUCTION}

Biodegradable polymers hold their houses for a confined time-frame in vivo and after that slowly debase into substances that could get to be dis-solvable or metabolized and discharged from the frame. With a particular give up aim to be utilized for as part of vivo programs the polymers applied for such frameworks should have perfect residences for bio-compatibility, process ability, sterilization capability, and shelf lifestyles. Bio-plastics are bio-based totally, biodegradable plastics with nearly similar houses to artificial plastics. Bio-degradation can be explained as a chemical procedure at some stage in which micro-organisms that gift inside the surroundings convert materials into herbal materials along with water, carbon dioxide, and compost. The time period bio-based totally way the material is partially derived from biomass (flora).

The petroleum based totally conventional plastics are non-renewable wherein the feed shares are bolstered through carbon fibres. Renewable aid feed stocks of plastics consist of polymers derived from microbial lifestyle bolstered with herbal fibre inclusive of cellulose, jute and so forth.

The accumulation of artificial, petroleum derived plastics inside the surroundings is a first-rate reason of pollution. So the approach to supply plastic, which is an important polymer utilized in our each day lifestyles, the usage of microbes (manufactured from microorganisms) is a unique technique. Artificial plastics continue to be within the surroundings for long term as they are immune to degradation. Bio-plastics are crafted from form of resources like polysaccharides, lipids and additionally proteins. Some examples of protein used as substrates for bio-plastic manufacturing are soy protein, wheat gluten, and rice and egg albumin. Those polymers can be metabolized and discharged by using typical physiological pathways. They may be characterized into 3 gatherings, in particular commonplace, semi synthetic, and engineered, taking into account their assets. Case of frequently utilized characteristic biodegradable polymers are gelatin, alginate, biodegradable polymers are a currently growing discipline.

Copyright @ 2019: This is an open-access article distributed under the terms of the Creative Commons Attribution license which permits unrestricted use, distribution, and reproduction in any medium for non commercial use (NonCommercial, or CC-BY-NC) provided the original author and source are credited. 


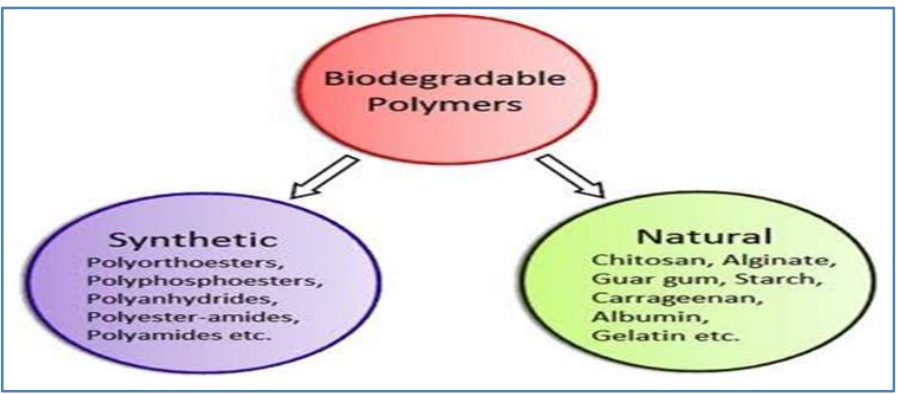

\section{Requirement for Biodegradable Polymers}

- It was seen that the careful ejection of a medicine depleted movement structure was problematic yet leaving non-biodegradable remote materials in the body for an uncertain timeframe made harmful quality issue.

- While spread controlled release is a fantastic strategy for achieving controlled medicine movement, it is limited by the polymer permeability also, the characteristics of a medicine extend, its scattering coefficient lessen.

- There is no necessity for a concise minute medical procedure for departure of Polymers.

- Avoid pressure ensuring Offer immense potential as the premise for controlled medicine transport.

\section{Bio-degradation}

The mechanical lead of biodegradable materials depends on upon their blend structure. The creation, the limit and taking care of attributes. The developing and the application conditions for whatever length of time that couple of decades, biodegradable polymers have been associated as bearers for controlled movement of low sub-nuclear weight drugs and also bio-active proteins. This is trailed by bio assimilation of the polymer pieces by microorganisms and their mineralization. Biodegradability relies upon the start of the polymer just as on its substance structure and the natural undermining conditions. Instruments what's more, estimation techniques of polymer bio-degradation have been investigated. Medications figured with these polymers can be released in a controlled manner by which the drug center in the target site is kept up inside the accommodating window. The release paces of the prescriptions from biodegradable polymers can be controlled.

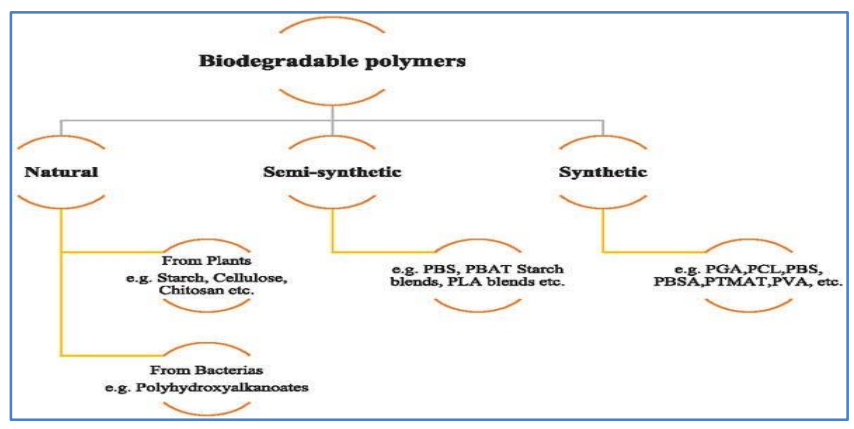

\section{Natural biodegradable polymers}

Bio-polymers are polymers shaped in nature during the development cycles everything being equal; henceforth, they are likewise alluded to as normal polymers. Their combination by and large includes compound catalyzed, chain development polymerization responses of actuated monomers, which are ordinarily framed inside cells by complex metabolic procedures.

\section{Synthetic Biodegradable Polymers}

There are diverse produced biodegradable polymers as of now being investigated as drug movement systems or on the other hand as stages for tissue planning. The methodology of biodegradable polymers has by and large influenced the progression and quick improvement of various advances in forefront medicate. Biodegradable polymers are generally used where the transient nearness of materials is required furthermore, they find applications as sutures, structures for tissue recuperation, tissue pastes, hemostats, and transient blocks for tissue bond, and furthermore cure movement structures. Each of these applications demands materials with extraordinary physical, substance, natural, and bio-mechanical properties to give capable treatment. In this way, a broad assortment of degradable polymers, both normal and designed, have been inspected for these applications. Anyway normal polymer amalgamation moving from source to source.

\section{Grouping and properties of bio-degradable polymers}

The biodegradable polymers can be characterized by their synthetic creation, beginning and combination technique, handling strategy, monetary significance, application, and so on. By and large, biodegradable polymers are ordered by their inception into two gatherings: common polymers which acquired from regular assets and manufactured polymers which delivered from oil. 


\section{The ideal conditions for bio-plastic blend and effect on changes of parameters}

PHB are lipid cellular, lipid granules which are framed by microbes under pressure conditions like confinements of supplements, for example, nitrogen, phosphorus, oxygen and so on and in overabundance of carbon. For the most part, in the generation of PHB alongside both nearness and nonappearance of supplements different elements like introductory culture $\mathrm{pH}$, culture temperature, pace of tumult.

\section{Impact of culture $\mathrm{pH}$}

Metabolic procedures require explicit $\mathrm{pH}$ to happen and slight change in $\mathrm{pH}$ influence the procedures and make those basic. It has likewise demonstrated that the creation of $\mathrm{PHB}$ is greatest at $\mathrm{pH} 7.0$.

\section{Impact of culture temperature}

Temperature additionally assume a noteworthy job in PHB generation. The PHB generation is most extreme at $30^{\circ} \mathrm{C}$.

\section{Impact of Agitation rate}

Unsettling rate additionally decides the development of strong bacterial strains and PHB generation. Legitimate tumult averts the bunching of cells into huge mass and consequently helps in the development. Tumult encourages every cell to use the supplements accessible in the way of life media. The pace of unsettling ought to be in the middle of $150-200 \mathrm{rpm}$ and on the off chance that it surpasses 200 , the generation diminishes due to extreme shear power because of tumult.

\section{Applications of biodegradable polymers}

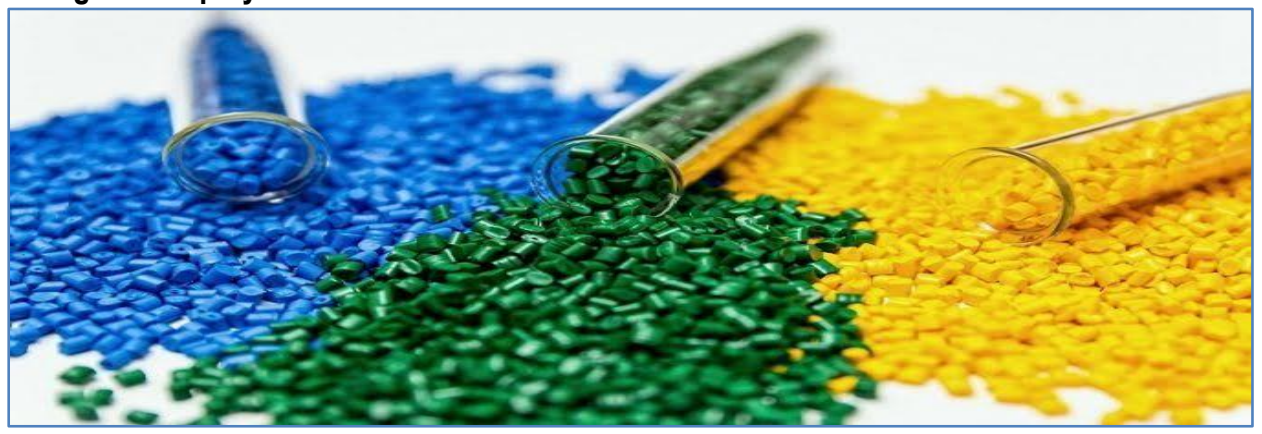

Bio-polymers that might be utilized in bundling keep on getting more consideration than those created for other people. All degrees of government, especially in China and Germany, are underwriting the far reaching utilization of biodegradable bundling materials so as to lessen the volume of idle materials discarded landfills, shortage of room. Innovative work to present a biodegradable polymer depends on the structure of materials with a theoretical application. It intended to supplant a current material or supplement one. Bio-polymers are chiefly valuable in drug, bundling, agribusiness and the car business. It is assessed that $41 \%$ of plastics are utilized in bundling, and that practically $50 \%$ of that volume is utilized to bundle nourishment items. BASF, a world head in the substance and plastic industry, is taking a shot at further advancement of biodegradable plastics dependent on polyester and starch. Eco-flex is a completely biodegradable plastic material that was acquainted with buyers by BASF in 2001.

The material is impervious to water, oil, clean for dispensable wrapping, disintegrate in typical fertilizing the soil frameworks. Utilization of a reasonable plastic mulch spread quickly following seeding expands the yield of spring wheat whenever utilized for under 40 days. In this way, plastic movies that start to debase in normal soil conditions after around one month are perfect as harvest mulches. Farming applications for bio-polymers are not restricted to film covers. Holders, for example, biodegradable plant pots and expendable fertilizing the soil compartments and packs are regions of intrigue. The pots are seeded straightforwardly into the dirt and it gets breakdown as the plant develops.

The fascination of bio-polymers in these territories is their inference from sustainable sources, easing back the consumption of constrained petroleum derivative stores. From the perspective of industry, the best favorable position of utilizing bio-polymers got from sustainable feed stocks is their minimal effort. At a first look, bio-polymers seem, by all accounts, to be a rewarding open door for the economy and the earth. In any case, similar to the circumstance with natural issues, a more intensive take a gander at the costexecution proportion of bio-polymers must be taken so as to settle on sound financial choices. One division in which monetary advantages exist from the utilization of bio-polymer materials is in the car business.

\section{Medicinal Applications}

\section{Wound administration}
- Sutures
- Staples
- Clips 
- Adhesives

- Surgical cross areas.

Orthopedic gadgets

- Pins

- Rods

- Screws

- Tacks

- Ligaments.

\section{Dental applications}

- Guided tissue recovery Membrane

- Void filler following tooth extraction.

\section{Cardiovascular applications}

- Stents.

\section{Intestinal applications}

- Anastomosis rings

\section{Medication conveyance framework}

- Tissue building.

\section{Pharmaceutical applications}

The polymers have a few applications in different measurements structures they have great bio-compatibility and low harmfulness properties in both ordinary recipient applications just as in novel applications.

\section{CONCLUSIONS}

The different methods of bio-degradation are likewise a key preferred position of such materials, since transfer techniques might be custom fitted to industry determinations. Ecological duty is continually expanding in significance to the two customers and industry. For the individuals who produce biodegradable plastic materials, it is a key preferred position. Bio-polymers limit carbon dioxide discharges during creation and corrupt to natural issue after transfer. There are boundless territories where biodegradable polymer materials may discover its utilization. The divisions of agribusiness, auto-motives, prescription, controlled medication discharge and bundling all require earth benevolent polymers. Because of bio-degradation custom fitted to explicit needs, every industry could make its own optimal material. The most encouraging procedures are those that utilize further advancement of biopolymer materials utilizing inexhaustible common assets.

Biodegradable polymers have demonstrated their potential for the improvement of new, progressed and proficient medication conveyance framework. In the zone of medication focusing on, there should be proceeding with accentuation on comprehension the association between polymeric particles and organic frameworks for example, blood parts, cell types (e. g., phagocytes), and cell receptors. Biodegradable polymers have gotten fundamentally more thought in the latest decades due their potential applications in the fields related to common protection and the help of physical prosperity. To upgrade the properties of biodegradable polymers, significant proportions of methods have been made, for instance, self-assertive and piece co-polymerization or joining. These techniques upgrade both the bio-degradation rate and the mechanical properties of the last things.

Biodegradable plastics containing starch and cellulose filaments have all the earmarks of being the well on the way to encounter ceaseless development in utilization. It is the ideal time for researcher and analysts to investigate the shrouded capability of characteristic riches existing as polymer and fiber, to use them and create biodegradable polymer for the advancement of science and innovation while supporting the contamination free condition.

\section{REFERENCES}

1. Chauhan, A., \& Kaith, B. (2012). Novel materials procured from surface modification of biomass. Waste and Biomass Valorization, 3(2), 141-148.

2. Chauhan, A., \& Kaith, B. (2011). Evaluation of Dynamic Materials Procured from Waste Biomass. ISRN Materials Science, 2011.

3. Chauhan, A., \& Kaith, B. (2012). Sorrel fiber as reinforcement in bio-composite. J. Environ. Sci. Technol, 5(5), 343-353.

4. Chauhan, A., \& Kaith, B. (2011). The Potential Use of Roselle as a Novel Graft Copolymer. Journal of natural fibers, 8(4), 308321. 
5. Chauhan, A., \& Kaith, B. (2012). Fabrication and Evaluation of Physico-chemico-thermally Resistant Bio-polymers. International Journal of Polymeric Materials, 61(12), 893-905.

6. Shivam, P. (2016). Recent developments on biodegradable polymers and their future trends. International Research Journal of Science and Engineering, 4, 17-26.

7. Chauhan, A., \& Kaith, B. (2010). Thermo-chemical evaluation of the roselle graft copolymers. Polymers from Renewable Resources, 1(4), 199-214.

8. Sawada, H. (1998). ISO standard activities in standardization of biodegradability of plastics-development of test methods and definitions. Polymer degradation and stability, 59(1-3), 365-370.

9. Lorcks J. Properties and applications of mater-bi starch-based materials. Polymer Degradation and Stability. $1998 ; 59$ (1-3):245249.

10. Bastioli, C. (1998). Properties and applications of Mater-Bi starch-based materials. Polymer Degradation and Stability, 59(1-3), 263-272.

11. Fomin, V. A., \& Guzeev, V. V. (2001). Biodegradable polymers, their present state and future prospects. International Polymer Science and Technology, 28(11), 76-84.

12. Blanco, A. (2002). Just add water. Plastics Engineering, 58(10), 6.

13. Guan, J., \& Hanna, M. A. (2002). Modification of macrostructure of starch acetate extruded with natural fibers (No. 026148). ASAE Paper.

14. Li, F. M., Guo, A. H., \& Wei, H. (1999). Effects of clear plastic film mulch on yield of spring wheat. Field Crops Research, 63(1), 79-86.

15. Huang, X., \& Brazel, C. S. (2001). On the importance and mechanisms of burst release in matrix-controlled drug delivery systems. Journal of controlled release, 73(2-3), 121-136.

16. Fonseca, C., Simoes, S., \& Gaspar, R. (2002). Paclitaxel-loaded PLGA nanoparticles: preparation, physicochemical characterization and in vitro anti-tumoral activity. Journal of controlled release, 83(2), 273-286.

17. Panyam, J., Dali, M. M., Sahoo, S. K., Ma, W., Chakravarthi, S. S., Amidon, G. L., ... \& Labhasetwar, V. (2003). Polymer degradation and in vitro release of a model protein from poly ( $\mathrm{D}, \mathrm{L}$-lactide-co-glycolide) nano-and microparticles. Journal of Controlled Release, 92(1-2), 173-187.

18. Chandra, R.U., Rustgi, R. (1998). Biodegradable polymers. Progress in polymer science 23: 1273-1335.

19. Huang, S.J., Bitritto, M., Leong, K.W., Pavlisko, J., Roby, M. (1978). JR Knox In: DL Allara and WL Hawkins (eds.) Adv Chem Ser, 169: 205.

20. Varnell, W.D., Harnson, I.R., Kosnioski, S.J. (1981). J Polym Sci Polym Phys Ed, 10: 1237-1263.

21. Blundell, D.J., Keller, A., Ward, I.M. (1966). J Polym Sci Polym Phys Ed, 4: 781.

22. Joshi, J.R., Patel, R.P. (2012). Role of biodegradable polymers in drug delivery. Int J Curr Pharm Res 4: 74-81.

23. Meredith, L. (2005). Hans Synthesis, characterization, and application of biodegradable polymeric prodrugs micelles for long-term drug delivery Doctor of Philosophy page no 8 A Thesis Submitted to the Faculty of Drexel University.

24. Edlund, U., Albertsson, A.C. (2002). Degradable polymer microspheres for controlled drug delivery. InDegradable aliphatic polyesters, 67- 112 .

25. Göpferich, A. (1996). Mechanisms of polymer degradation and erosion. Biomaterials, 17: 103-14.

26. Göpferich, A. (1997). Polymer bulk erosion. Macromolecules, 30: 2598- 2604.

27. Maeda, M., Moriuchi, S., Sano. A., Yoshimine, T. (2002). New drug delivery system for water-soluble drugs using silicone and its usefulness for local treatment: application of GCV-silicone to GCV/HSV-tk gene therapy for brain tumor. Journal of controlled release. $84: 15-25$.

28. Lucas, N., Bienaime, C., Belloy, C., Queneudec, M., Silvestre, F. (2008) Polymer biodegradation: Mechanisms and estimation techniques-A review. Chemosphere. 73: 429-442.

29. Willett, J.L. (1994). Mechanical properties of LDPE/granular starch composites. Journal of Applied Polymer Science. 54: 16851695.

30. Cho, J.W., Woo, K.S., Chun, B.C., Park J.S. (2001). Ultraviolet reflective and mechanical properties of polyethylene mulching films. European polymer journal. 37: 1227-1232.

31. Jasberg, B., Swanson, C., Nelsen, T., Doane, W. (1992). Mixing polyethylenepoly (ethylene-co-acrylic acid) copolymer-starch formulations for blown films. ARS reprints collection.

32. Lawton, J.W. (1996). Effect of starch type on the properties of starch containing films. Carbohydrate Polymers, 29: 203-208.

33. Briassoulis, D. (2006). Mechanical behaviour of biodegradable agricultural films under real fieldconditions. Polym Deg Stab, 91 : 1256-1272. 